ISSN 0258-7122

Bangladesh J. Agril. Res. 34(1) : 67-73, March 2009

\title{
EVALUATION OF GROWTH AND YIELD OF SELECTED HYBRID AND INBRED RICE VARIETIES GROWN IN NET-HOUSE DURING TRANSPLANTED AMAN SEASON
}

\author{
ISLAM, M. SH ${ }^{1}$, M.S.U. BHUIYA ${ }^{2}$, A.R. GOMOSTA ${ }^{3}$ \\ A.R. SARKAR ${ }^{2}$ AND M.M. HUSSAIN ${ }^{5}$
}

\begin{abstract}
Pot experiments were conducted during T. aman 2001 and 2002 (wet season) at Bangladesh Rice Research Institute (BRRI) in net house. Hybrid variety Sonarbangla-1 and inbred modern variety BRRI dhan-31 were used in both the seasons and BRRI hybrid dhan-l was used in 2002. The main objective of the experiments was to compare the growth and yield behaviour of hybrid and inbred rice varieties under controlled condition. In 2001, BRRI dhan-3l had about $10-15 \%$ higher plant height, very similar tillers/plant, 15-25\% higher leaf area at all days after transplanting (DAT) compared to Sonarbangla-1. Sonarbangla- 1 had about 40\% higher dry matter production at 25 DAT but had very similar dry matter production at 50 and 75 DAT, 4-11\% higher rooting depth at all DATs, about 22\% higher root dry weight at 25 DAT, but 5-10\% lower root dry weight at 50 and 75 DAT compared to BRRI dhan-31. The photosynthetic rate was higher $\left(20 \mu \mathrm{mol} \mathrm{m} / \mathrm{sec}^{-1}\right)$ in BRRI dhan-3l at 35 DAT (maximum tillering stage) but at 65 DAT, Sonarbangla-l had higher photosynthetic rate of $19.5 \mu \mathrm{mol} \mathrm{m} \mathrm{m}^{-2} \mathrm{sec}^{-1}$. BRRI dhan-3l had higher panicles/plant than Sonarbangla-1, but Sonarbangla-1 had higher number of grains/panicle, 1000-grain weight and grain yield than BRRI dhan-31. In 2002, BRRI dhan-31 had the highest plant height at 25 DAT, but at 75 DAT, BRRI hybrid dhan-l had the highest plant height. Sonarbangla- 1 had the largest leaf area at 25 and 50 DAT followed by BRRI dhan-31, but at 75 DAT, BRRI dhan31 had the largest leaf area. The highest shoot dry matter was observed in BRRI dhan-31 followed by Sonarbangla-1 at all DATs. Sonarbangla-1 had the highest rooting depth and root dry weight at all DATs. BRRI dhan-31 gave the highest number of panicles/plant followed by Sonarbangla-I, BRRI hybrid dhan-l had the highest grains/panicle followed by BRRI dhan-31 and Sonarbangla-I had the highest 1000-grain weight followed by BRRI dhan-31. The highest amount of grains/plant (34.6 g) was obtained from BRRI dhan-31.
\end{abstract}

Key Words: Shoot dry matter, root dry weight, leaf area, photosynthesis, grain yield.

\section{Introduction}

Hybrid rice technology is one of the alternative means to meet the challenge of food security for the increasing population in Bangladesh. Chinese rice scientists

\footnotetext{
${ }^{1}$ Senior Scientific Officer, Agronomy Division. BRRI, ${ }^{2 \& 4}$ Professor, Deptt of Agronomy, BAU, ${ }^{3}$ Former Director (Res.), BRRI, ${ }^{5}$ Ccief Scientific Officer, ARD, BRRI.
} 
developed and used commercial rice hybrid, which increased rice yield by about $20 \%$ over the semi-dwarf varieties (Yuan et al., 1994). Many hybrid rice varieties outyielded the standard check variety with same growth duration by more than are t/ha (Julfiquar et al., 1998).

The heterosis for higher yield in hybrid rice comes from vegetative growth. The life cycles of hybrid and inbred rice are almost similar, but hybrid rice is more vigorous in the vegetative phase, especially at seedling stage. Hybrid rice has higher seedling dry matter content, thicker leaves, larger leaf area and longer root system (BRRI, 2000). Hybrid rice can give 10-15\% yield advantage over modern inbred varieties through vigorous growth, extensive root system. efficient and greater sink size, higher carbohydrate translocation from vegetative parts to spikelets and larger leaf area index during the grain filling stage (Peng et al., 1998). However, the physiological basis for heterosis remains unknown. Again the inbred is normally sink limiting and hybrids are source limiting. For high yield of hybrid rice, sink is not the limiting factor as it is in inbred rice (Yan, 1988). Two-step grain filling is observed in hybrid rice, which means that pollinated spikelets stop development for several days but maintain the ability to fill later (Wen, 1990). During vegetative growth, hybrid rice accumulates more dry matter which results in higher spikelets/panicle, whereas inbred rice depends basically on the accumulation of assimilates after heading (Yan, 1988). The main reason for higher yield of hybrid rice is vigorous seedlings with tillers. The tillers that emerge in the seedbed produce more spikelets/panicle than the tillers that emerge after transplanting (Wen, 1990).

The common properties of modern inbred and hybrid rice varieties are, high nitrogen response, erect and thick leaves which remain green till maturity, short statured and high harvest index. Dry matter production at different growth stages shows different patterns for hybrid and inbred rice. While hybrid rice has more dry matter accumulation in the early and middle growth stages, inbred rice has more in the late growth stages (Yan, 1988). High grain yield of hybrid rice is attributed to high vegetative biomass production, high leaf area, large panicles and high tillering capacity in some cases (Peng et al., 1998). The present study was undertaken to evaluate the growth and yield behaviour of a few selected hybrid and inbred rice varieties in wet season under controlled condition.

\section{Materials and Method \\ Design and treatments}

The experiment was conducted using a completely randomized design with 3 replications, where varieties were considered as treatments. The 2 hybrid rice 
varieties were Sonarbangla-l and BRRI hybrid dhan-1 (only in 2002) and an inbred rice BRRI dhan-31.

\section{Number, size and arrangement of pots and condition of the net house}

A total of 28 earthen pots in 2001 and 42 in 2002 [14 pots for each variety, 3 pots for each sampling ( $3 \times 3$ pots) and 5 pots for yield data] were taken with about I 2 $\mathrm{kg}$ muddy soil in each pot. The soil was silty clay with O.M 2.1\%, pH 6.4-6.7 and total $\mathbf{N} 0.13 \%$. The pots were kept in the net house. The size of the pots was: 12 inches in height, 20 inches diameter at the top and 9 inches at the bottom. The pots were arranged in the net house in rows variety-wise. The net house was a ware-net covered and well protected chamber. Sunlight and rain could enter easily into the net house.

\section{Fertilization and transplanting in the pots}

Considering the weight of top-soil $(0-15 \mathrm{~cm})$ of the field $\left(6 \times 10^{5} \mathrm{~kg} / \mathrm{ha}\right)$, the pots with $10 \mathrm{~kg}$ soil were fertilized @ 100-26.4-41.5-10-5 kg N, P, K, S and Zn/ha, respectively. All the fertilizers were applied as basal except urea, which was top dressed in 3 equal splits at 15, 30, and 45 days after transplanting. Single 30-day old healthy seedling was transplanted in the middle of each pot. The pots were irrigated with watering can before crack development on the surface soil of the earthen pots.

\section{Measurement of growth parameters and photosynthesis}

The growth parameters e.g., plant height, tillers/plant, leaf area, rooting depth, shoot and root dry matter were measured from destructive samples. To compare the photosynthetic rate of hybrid (Sonarbangla-1) and inbred (BRRI dhan-31) rice varieties, their photosynthetic efficiency was measured in 2001 with a portable photosynthesis-measuring instrument (LiCOR-6200) at 35 DAT (maximum tillering stage) and at 65 DAT (Booting to flower initiation stage) in clear sunshine at 11 to $12 \mathrm{hrs}$. The SPAD reading of the varieties was also recorded at the same time.

\section{Results and Discussion}

\section{Seedling quality}

Seedling quality of Sonarbangla-1 was better in terms of all parameters studied i.e., plant height, tiller number, leaf area, rooting depth, shoot and root dry weight, root-shoot ratio and vigour index compared to BRRI hybrid dhan-l and BRRI dhan-31 (Table 1). 
Table 1. Parameters of seedling quality of different transplanted aman rice.

\begin{tabular}{|c|c|c|c|c|c|c|c|c|c|c|}
\hline \multicolumn{11}{|c|}{2001 (At 30 DAS) } \\
\hline Variety & $\begin{array}{l}\text { Plant } \\
\text { eight } \\
(\mathrm{cm})\end{array}$ & $\begin{array}{c}\text { Tillers/ } \\
\text { plant }\end{array}$ & $\begin{array}{c}\text { Leaf } \\
\text { no./ } \\
\text { plant }\end{array}$ & $\begin{array}{l}\mathrm{LA} / \\
\text { plant } \\
\left(\mathrm{cm}^{2}\right)\end{array}$ & $\begin{array}{l}\text { Root } \\
\text { depth } \\
\left(\mathrm{cm}^{2}\right)\end{array}$ & $\begin{array}{l}\text { Shoot } \\
\text { dry wt } \\
\text { (g } \\
\text { /plant) }\end{array}$ & $\begin{array}{l}\text { Root- } \\
\text { dry wt } \\
\text { (g } \\
\text { /plant) }\end{array}$ & $\begin{array}{c}\text { Root } \\
\text { Shoot } \\
\text { ratio }\end{array}$ & $\begin{array}{l}\text { Wt: } \\
\text { Height }\end{array}$ & $\begin{array}{l}\text { Vigour } \\
\text { index }\end{array}$ \\
\hline SB-I & 29.6 & 2 & 7 & 23 & 19.4 & 0.214 & 0.087 & 0.405 & 0.07 & $9 *$ \\
\hline BR-31 & 28.9 & 1 & 7 & 14 & 18.0 & 0.207 & 0.079 & 0.308 & 0.07 & 8 \\
\hline \multicolumn{11}{|c|}{2002 (At 30 DAS) } \\
\hline SB-1 & 33.0 & 2 & 6 & 27 & 10.0 & 0.116 & 0.079 & 0.681 & 0.04 & 9 \\
\hline BH-1 & 32.2 & 1 & 4 & 25 & 12.0 & 0.097 & 0.051 & 0.526 & 0.03 & 8 \\
\hline BR-31 & 30.7 & 1 & 4 & 22 & 10.0 & 0.087 & 0.033 & 0.379 & 0.03 & 7 \\
\hline
\end{tabular}

*Visual Score:1= Very poor growth, 3= Poor growth, 5= Medium growth, 7= Good growth and 9 Excellent; SB-I= Sonarbangla-1, BH-I= BRRI hybrid dhan-l and BR-31 = BRRI dhan-3l.

\section{Growth parameters}

It was observed that plant height and leaf area of BRRI dhan-31 were higher than those of Sonarbangla-l at all growth stages, but the number of tillers/plant was almost identical (Table 2). Shoot dry weight (stem + leaf) of Sonarbangla-1 was much higher than that of BRRI dhan-31 at 25 DAT, but it was very similar at 50 and 75 DAT. Rooting depth of Sonarbangla-I was about $15 \%$ higher than that of BRRI dhan-31 at all DATs, but root dry weight was $23 \%$ higher in SonarbanglaI only at 25 DAT. The root dry weight of BRRI dhan-31 was higher than that of Sonarbangla-l at 50 and 75 DAT (Table 2) during T. aman season of 2001. Lower root dry weight with higher rooting depth might be due to thinner roots.

During T. aman 2002, the tallest plant was observed in BRRI dhan-31 at 25 DAT and in BRRI hybrid dhan-l at 50 and 75 DAT. The highest number of tillers/plant was observed in Sonarbangla-l at 25 DAT, but in BRRJ dhan-3l at 50 and 75 DAT. Sonarbangla-l had the largest leaf area at 25 and 50 DAT followed by BRRI dhan-31 but at 75 DAT, BRRI dhan-31 had the largest leaf area. The highest shoot (stem + leaf) dry weight was observed in BRRI dhan-31 followed by Sonarbangla-1 at all DATs. Sonarbangla-l had the highest rooting depth and root dry weight at all DATs (Table 2) during T. aman 2002. The results revealed that Sonarbangla-1 had much higher root dry weight at early growth stage (25 DAT) in both the seasons. Similar results were also reported by Yang and Sun (1986), who observed larger and deeper root systems in hybrid rice compared to the conventional varieties. The superficial roots of hybrids were more developed and heavier than those of the inbred. 
Table 2. Plant growth parameters of different varieties at different DAT in T. aman season.

\begin{tabular}{|c|c|c|c|c|c|c|c|c|}
\hline \multirow[t]{2}{*}{ Variety } & \multirow{2}{*}{$\begin{array}{c}\text { Plant } \\
\text { ht. (cm) }\end{array}$} & \multirow{2}{*}{$\begin{array}{l}\text { Tillers/ } \\
\text { plant }\end{array}$} & \multirow{2}{*}{$\begin{array}{l}\mathrm{LA} / \\
\text { plant } \\
\left(\mathrm{cm}^{2}\right)\end{array}$} & \multirow{2}{*}{$\begin{array}{c}\text { Rooting } \\
\text { depth } \\
(\mathrm{cm})\end{array}$} & \multicolumn{3}{|c|}{ Shoot dry wt (g/plant) } & \multirow{2}{*}{$\begin{array}{l}\text { Root dry } \\
\text { wt } \\
\text { (g/ plant) }\end{array}$} \\
\hline & & & & & Stem & leaf & Total & \\
\hline \multicolumn{9}{|c|}{25 DAT } \\
\hline SB-1 & $60.7 \pm 1.5$ & $9 \pm 0.33$ & $542 \pm 20.5$ & $28.0 \pm 0.52$ & $6.5 \pm 0.29$ & $4.7+0.31$ & $11.27 \pm 0.6$ & $2.17+0.10$ \\
\hline BR-31 & $70.1 \pm 1.1$ & $9 \pm 0.33$ & $692 \pm 29.7$ & $25.1 \pm 0.49$ & $4.7 \pm 0.15$ & $3.3 \pm 0.16$ & $7.93 \pm 0.3$ & $1.67 \pm 0.14$ \\
\hline \multicolumn{9}{|c|}{$50 \mathrm{DAT}$} \\
\hline SB-1 & $78.2 \pm 0.6$ & $15 \pm 0.8$ & $1523 \pm 41$ & $32.1 \pm 1.05$ & $21.1 \pm 0.7$ & $9.9 \pm 0.32$ & $31.03 \pm 0.9$ & $5.53 \pm 0.25$ \\
\hline BR-3I & $80.0 \pm 0.8$ & $14 \pm 1.0$ & $1647 \pm 30$ & $30.5 \pm 1.29$ & $23.6 \pm 0.6$ & $8.7 \pm 0.12$ & $32.00 \pm 0.7$ & $6.70 \pm 0.45$ \\
\hline \multicolumn{9}{|c|}{75 DAT } \\
\hline SB-1 & $91.3 \pm 1.2$ & $16 \pm 0.5$ & $1582 \pm 24$ & $34.6 \pm 0.91$ & $25.7 \pm 0.4$ & $10.2 \pm 0.29$ & $35.87 \pm 0.7$ & $7.30 \pm 0.37$ \\
\hline BR-31 & $99.3 * 1.1$ & $17 \pm 1.0$ & $1853 \pm 52$ & $33.3 \pm 1.14$ & $25.7 \pm 0.5$ & $10.9 \pm 0.34$ & $36.60 \pm 0.9$ & $8.40+0.35$ \\
\hline \multicolumn{9}{|c|}{$\begin{array}{c}2002 \\
25 \text { DAT }\end{array}$} \\
\hline SB-1 & $70.4 \pm 0.8$ & $11.7 \pm 0.5$ & $353 \pm 10$ & $30.3 \pm 0.7$ & $2.35 \pm 0.1$ & $1.78 \pm 0.05$ & $4.14 \pm 0.1$ & $3.50 \pm 0.12$ \\
\hline BR-1 & $77.4 \pm 0.9$ & $9.7 \pm 0.19$ & $269 \pm 2.4$ & $28.1 \pm 0.5$ & $1.91 \pm 0.0$ & $1.72 \pm 0.02$ & $3.63 \pm 0.0$ & $1.33 \pm 0.01$ \\
\hline BR31 & $82.3 \pm 1.8$ & $8.0 \pm 0.33$ & $323 \pm 6.2$ & $28.3 \pm 0.6$ & $3.14 \pm 0.0$ & $2.44 \pm 0.05$ & $5.58 \pm 0.0$ & $1.80 \pm 0.03$ \\
\hline \multicolumn{9}{|c|}{$50 \mathrm{DAT}$} \\
\hline SB-1 & $87.4 \pm 1.9$ & $18.0 \pm 0.7$ & $1854 \pm 67$ & $36.0 \pm 0.7$ & $16.1 \pm 0.7$ & $10.23 \pm 0.5$ & $26.33 \pm 1$ & $3.36+0.20$ \\
\hline BH-1 & $101.5 \pm 1$ & $18.7 \pm 1.0$ & $1633 \pm 45$ & $31.0+0.7$ & $10.8 \pm 0.4$ & $8.41 \pm 0.71$ & $19.16 \pm 1$ & $2.50+0.15$ \\
\hline BR-31 & $97.3 \pm 1.6$ & $20.7 \pm 0.5$ & $1759 \pm 21$ & $30.5 \pm 0.7$ & $17.7+0.5$ & $10.98 \pm 0.6$ & $28.70 \pm 1$ & $2.62+0.14$ \\
\hline \multicolumn{9}{|c|}{75 DAT } \\
\hline SB-1 & $102.3 \pm 1.0$ & $21.7 \pm 0.8$ & $2662 \pm 69$ & $35.0+1.7$ & $19.8 \pm 0.7$ & $7.9 \pm 0.38$ & $27.7 \pm 1.1$ & $5.22+0.12$ \\
\hline BH-1 & $121.3 \pm 1.4$ & $18.7 \pm 0.4$ & $2145 \pm 52$ & $34.7+1.9$ & $18.8 \pm 0.7$ & $8.8 \pm 0.28$ & $27.6 \pm 1.0$ & $5.14+0.23$ \\
\hline BR-31 & $116.7 \pm 0.5$ & $22.7 \pm 1.0$ & $2860 \pm 89$ & $32.3+1.2$ & $25.5 \pm 1.1$ & $11.0 \pm 0.4$ & $36.5 \pm 1.5$ & $5.07 \pm 0.18$ \\
\hline
\end{tabular}

*SB-l= Sonarbangla-1, BH-1= BRRI hybrid dhan-l and BR-31= BRRI dhan-3l; $\mathrm{LA}=$ leaf area, \pm stands for standard error from the mean value

\section{Photosynthesis}

The photosynthetic rate $\left(\mu \mathrm{mol} \mathrm{m}^{-2} \mathrm{sec}^{-1}\right)$ in BRRI dhan-3l was higher than hybrid Sonarbangla-1 at 35 DAT (early growth stage), but lower at 65 DAT (flower initiation stage) (Table 3). Results also indicated that photosynthetic rate was higher in the leaves with higher SPAD reading indicating that photosynthetic rate was higher in the leaves where N concentration is higher. Similar results were reported by Peng et al. (1998) who observed a strong relationship $\left(\mathrm{R}^{2}=0.84\right)$ between photosynthetic rate and $\mathrm{N}$ concentration of the flag leaves. Miah et al. 
(1997) also reported higher photosynthetic rate, which was associated with higher leaf chlorophyll content (SPAD value basis).

Table 3. Photosynthesis rate of two varieties at different DAT in T. aman season, 200135 DAT.

\begin{tabular}{llcll}
\hline Variety & SPAD value & $\mathrm{CO}_{2}$ conc. $(\mathrm{ppm})$ & $\mathrm{P}\left(\mu \mathrm{mol} \mathrm{m}^{-2} \mathrm{sec}^{-1}\right)$ \\
\hline SB-1 & 39.4 & 387 & 19.6 \\
BR-31 & 40.9 & 387 & 20.0 \\
\hline \multicolumn{4}{c}{ 65 DAT } \\
\hline SB-1 & 47.9 & 375.3 & 19.5 \\
BR-31 & 45.0 & 384.8 & 15.8 \\
\hline
\end{tabular}

SB1 $=$ Sonarbangla -1 and BR-31 = BRRI dhan-3l .

\section{Growth parameters at harvest, yield components and grain yield}

At harvest, plant height, tiller number, yield components, grain yield, sterility (\%) and HI were measured during T. aman 2001 and 2002. In T. aman 2001, BRRI dhan-3l had higher plant height, number of tillers/plant, and number of panicles/plant than Sonarbangla-1, but Sonarbangla-1 had more number of grains/panicle, 1000-grain weight and grain yield than that of BRRI dhan-31. The sterility (\%) of BRRI dhan-31 was much higher than that of Sonarbangla-1, which might be due to genetic character of BRRI dhan-31. Higher sterility of BRRI dhan-31 decreased the HI and ultimately reduced grain yield of this variety (Table 4) in 2001.

Table 4. Growth parameters at harvest, grain yield and yield components of $T$. aman season 2001.

\begin{tabular}{l|c|c|c|c|c|c|c|c}
\hline Variety & $\begin{array}{c}\text { Plant ht. } \\
(\mathrm{cm})\end{array}$ & $\begin{array}{c}\text { Tillers/ } \\
\text { plant }\end{array}$ & $\begin{array}{c}\text { Panicles/ } \\
\text { plant }\end{array}$ & $\begin{array}{c}\text { Grains/ } \\
\text { panicl }\end{array}$ & $\begin{array}{c}1000-G W \\
(\mathrm{~g})\end{array}$ & $\begin{array}{c}\text { Yield } \\
(\mathrm{g} / \text { plant })\end{array}$ & $\begin{array}{c}\text { Sterility } \\
(\%)\end{array}$ & HI \\
\hline SB-1 & $102 \pm 0.92$ & $13.6 \pm 0.5$ & $11.4 \pm 0.4$ & $91 \pm 1.96$ & $26.06 \pm 0.09$ & $25.96 \pm 0.61$ & $20.6 \pm 0.8$ & $0.48 \pm 0$ \\
BR-31 & $111 \pm 1.22$ & $15.0 \pm 0.5$ & $13.8 \pm 0.4$ & $58 \pm 1.44$ & $24.12 \pm 0.14$ & $20.09 \pm 1.26$ & $40.0 \pm 1.9$ & $0.44 \pm 0$ \\
& & & \multicolumn{7}{c}{2002} & & & & \\
SB-1 & $106 \pm 0.88$ & $21 \pm 0.84$ & $19 \pm 1.16$ & $65 \pm 3.79$ & $25.5 \pm 0.12$ & $32.2 \pm 1.07$ & $22 \pm 0.84$ & $0.47 \pm 0$ \\
BH-1 & $113 \pm 0.51$ & $18 \pm 0.51$ & $17 \pm 0.33$ & $79 \pm 2.04$ & $23.2 \pm 0.05$ & $31.2 \pm 1.10$ & $24 \pm 2.00$ & $0.46 \pm 0$ \\
BR-31 & $110 \pm 1.07$ & $22 \pm 1.64$ & $20 \pm 1.26$ & $70 \pm 2.01$ & $24.4 \pm 0.11$ & $34.6 \pm 2.48$ & $37 \pm 0.39$ & $0.48 \pm 0$ \\
\hline
\end{tabular}

SB-1= Sonarbangla-1, BH-1= BRRI hybrid dhan-l and BR31= BRRI dhan-3l, \pm stands for standard error from the mean value

In 2002, BRRI hybrid dhan-l had the highest plant height followed by BRRI dhan-31. BRRI dhan-31 gave the highest number of tillers/plant (22) and panicles/plant (20), which was followed by Sonarbangla- 1. Sonarbangla- I had 
the highest 1000-grain weight of $26 \mathrm{~g}$ followed by BRRI dhan-31. BRRI dhan-31 had the highest grain yield/plant followed by Sonarbangla-I. Again, BRRI dhan31 had the highest sterility of $37 \%$, which might be its genetic character. Harvest index (HI) was the highest in BRRI dhan-31, which resulted in the highest grain yield of $34.6 \mathrm{~g}$ /plant in 2002 (Table 3). Compared to 2001 with high pest infestation, all tested varieties produced 15-30\% higher grain yield during 2002.

\section{Conclusion}

Sonarbangla-1 produced much higher root dry matter and vigorous shoot growth at seedling stage compared to other hybrid and inbred varieties. The vigorous growth of tested hybrid rice at early growth stage could not increase the grain yield. Poor grain yield of hybrid rice is mainly caused by high pest infestation and grain sterility in T. aman (wet) season.

\section{References}

BRRI (Bangladesh Rice Research Institute). 2000. Annual Report for 1999-2000. Bangladesh Rice Res. Inst., Joydebpur, Gazipur. p. 138.

Julfiquar, A.W., M.M. Haque, A.K.G.M.E. Haque and M.A. Rashid. 1998. Current status of hybrid rice research and future program in Bangladesh. Paper presented at BARC in the Workshop on Development and Use of Hybrid Rice in Bangladesh.

Miah, M. N. H, T. Yoshida, and Y. Yamamoto. 1997. Effect of nitrogen application during ripening period on photosynthesis and dry matter production and its impact on rice yield and yield components of semi-dwarf indica rice varieties under water culture conditions. Soil Sci. Plant Nutr. 43 (1): 205-2 17.

Peng, S., J.U.Y. ang, F.V. Carcia and R.C. Laza, 1998. Physiology based crop management for yield maximization of hybrid rice. In: Advances in hybrid rice technology. Proc. 3 Intl. Symp. on Hybrid rice. IRRI, Los Banos, Philippines.

Wen, Z. 1990. Techniques of Seed Production and Cultivation of Hybrid Rice. Beijing China. Agricultural Press.

Yan, Z. D. 1988. Agronomic management of rice hybrid compared with conventional varieties. In: "Hybrid Rice”. Intl. Rice. Res. Inst., Manila, Philippines. pp. 2 17-223.

Yang, H. and X. Sun. 1986. Physiological characteristics of hybrid rice roots. In: Hybrid rice. International Rice research Institute, p. 281.

Yuan, L.P., Z.Y. Yang and J.B. Yang. 1994. Hybrid rice in China. In "Hybrid Rice TechnologyNew Developments and Future Prospects”. (S.S. Virmani, Ed.), pp. 143147. Intl. Rice Res. Inst., Manila, Philippines. 